\title{
A Cross-Cultural Study of Apology Speech Act Realizations
}

\author{
Nawamin Prachanant
}

\begin{abstract}
Different cultural backgrounds may perform different semantic formulas. This study aimed to investigate the occurrences of apology speech acts in two dimensions of semantic formulas: frequency and pattern. The participants for this study were 32 English native speakers and 32 Thai EFL learners, in a total of 64. Participants responded to 10 apologizing in a written discourse completion task (DCT) that simulated apology-provoking situations. The responses from the DCTs were coded according to the apology taxonomy. The data were then analyzed according to the frequency and pattern of the semantic formulas used by the two different groups of participants. The findings revealed that the three most frequently used semantic formulas of two groups were "Expression of apology", “Offering repair", and "Explanation", respectively. Also, the three most patterns of semantic formulas found in the two groups were "Expression of apology + Offering repair", followed by "Expression of apology + Explanation", and "Expression of apology + Offering repair + Showing concerns", respectively.

The findings suggest opportunities for building cross-cultural communications across continents. The results have implications for teaching and learning of English as an $\mathrm{L2}$ in the cross-cultural contexts.
\end{abstract}

Index Terms-Apology strategy, cross-cultural study, social status, speech act.

\section{INTRODUCTION}

Since Hymes [1] first introduced the concept of communicative competence', which is the ability to employ linguistic forms in order to communicate appropriately in social interaction, it has been recognized as important in the development of the interlanguage of second or foreign language learners. This has been the focus of the studies of interlanguage pragmatics, the branch of second language research which studies how non-native speakers understand and carry out linguistic actions in a target language, and how they acquire second language (L2) knowledge [2]. It can be said that successful and effective speaking of $\mathrm{L} 2$ learners is not just a matter of using grammatically correct words and forms, but also knowing when to use them and under what circumstances [3], [4].

This has led to the study of cross-cultural and interlanguage pragmatics which focuses on the study of non-native speakers' use and acquisition of linguistic patterns in a second language [5]. Much attention in cross-cultural and interlanguage pragmatics has been devoted to learners' performance of speech acts in the second language. Speech

Manuscript received March 28, 2016; accepted September 25, 2016.

Nawamin Prachanant is with Buriram Rajabhat University, Thailand (e-mail: nawaminpt@yahoo.com). acts, as one way to investigate pragmatics are "the basic or minimal units of linguistic communication" [6]. Requesting, complimenting and apologizing are examples of speech acts which demonstrate the intentions of the speakers. The ability to perform various speech acts is an important part of the development of communicative competence [7]. Therefore, a substantial body of empirical research has emerged describing speech acts performed by non-native speakers of various linguistic and cultural backgrounds [4], [8]-[15].

In the past four decades, the speech act of apologies has also been investigated cross-culturally and some similarities and differences have been found between cultures in the use of apologies [4], [8]-[11], [13]-[27]. The studies mentioned above have been carried out in second or foreign language learning situations. The studies which have been carried out in Thai EFL situation are the studies of [13], [22]. They have carried out studies on the use of apologies in a foreign language learning situation with EFL learners in Thailand and found out differences resulting from the culture of the learners.

This study, therefore, attempts to provide some insights into the norms and patterns of apology strategies used by native English speakers (NE) comparing with the producing of those strategies of Thai EFL learners. The findings of this study could be of great help in the teaching and learning of foreign languages in relation to cultures, like teaching Thai to speakers of other languages or teaching English to Thais as well as in developing a syllabus for communicative English courses in order to enhance one's ability to communicate effectively in a cross-cultural setting without facing any communication breakdowns.

\section{PURPOSES OF THE STUDY}

1. To investigate the typical apology strategies produced by English native speakers and Thai EFL learners.

2. To investigate the patterns of semantic formulas used by English native speakers and Thai EFL learners.

\section{THE SPEECH ACT OF APOLOGY}

Apologies are 'expressive' illocutionary act [28] and 'convivial' speech acts, the goal of which coincides with the social goal of maintaining harmony between speaker and hearer. Apologies typically occur post-event in an adjacency pair and involve interactions in which the apologizer attempts to restore harmony when an offence has been committed, but there is also an element of face-saving involved with a protective orientation towards saving the interlocutor's face and a defensive orientation towards saving one's own face 
[15].

Goffman [29] undertook the study of apologies which he termed 'remedial interchanges', focusing on the description of the remedial work necessary to transform the perceived offensive meaning of an act into an acceptable one. Such a task could be accomplished through accounts, apologies and requests. Goffman states that a speaker can perform an apology by: 1) expressing embarrassment; 2) stating his/ her knowledge of proper behavior; 3) sympathizing with the application of negative sanction; 4) repudiation of his/ her own behavior; 5) showing contempt for oneself; 6) promising to embrace the "right way"; and 7) proffering penance and restitution.

Taking for granted that the act of apology is one type of remedial work, Fraser [30] continued an analysis and description of the 'semantic formulas' which are used to perform an apology. Fraser mentions that speakers apologize not only by expressing 'regret' (I'm sorry), but also by requesting 'forgiveness' (Forgive me for ...), by acknowledging their 'responsibility' (It was my fault.), by promising 'forbearance' (It'll never happen again.), or by offering 'redress' (Let me pay for the damages.). Fraser also points out that in cases where social norms are broken, speakers tend to add an 'account/ explanation' of the situation to their apology formula.

Using as a starting point Fraser's description of the semantic formulas employed in producing an apology, Olshtain and Cohen [10] came up with a more detailed classification, which constitutes the core of all the categorizations used in the studies of apology. Olshtain and Cohen describe apology as 'a speech act set' which is comprised of five potential semantic formulas as follows:

1. Expression of an Apology or Illocutionary Force Indicating Device (IFID)-this formula can be classified into three sub-strategies: expressing regret (e.g. I am sorry,), offering apology (e.g. I apologize.), and requesting forgiveness (e.g. Excuse me. / Forgive me.);

2. Acknowledgement of responsibility-there are three sub-categories: accepting blame (e.g. It's my fault.), expressing self-deficiency (e.g. I wasn't thinking.), and recognizing that the other person deserves an apology (e.g. You are right.);

3. Explanation or account-this formula varies according to the context (e.g. I was sick. / There was an accident. / I forgot. /I had to work.);

4. Offer of repair-this formula occurs only in certain contexts (e.g. I'll pay .../ Let me help you.);

5. Promise of forbearance-this formula occurs only in certain contexts (e.g. It won't happen again.)

When offenders need to apologize, they have the previous set of formulas as shown above to use/ explain in the offensive act. On the other hand, when offenders do not need to apologize, they have a number of options, which are classified, but not analyzed by Olshtain and Cohen as follows:

1. No verbal reaction (opt out);

2. Denial of the need to apologize (e.g. No need for you to get insulted);

3. Denial of responsibility-this formula can be categorized into two types: not accepting the blame (e.g. It wasn't my fault.), and blaming others (e.g. It's your fault.).
Olshtain and Cohen's categorization of apology strategies is developed and employed in studies of L1 and L2 in a variety of languages [3], [9], [11], [13], [15], [21], [22], [24]. However, the most interesting study, which is utilized in the present study, was conducted by Prachanant [13]. His study was focused on how to respond to complaints in the hotel business and he states that reactions to complaint in the hotel business can be performed using one or more of twelve apology strategies or semantic formulas. The semantic classification of the twelve formulas is as follows:

1. Expression of Apology (e.g. I (do) apologize. / I'm (very, really, terribly, extremely) sorry. /Excuse me.);

2. Acknowledgement of Responsibility (e.g. Yes, sir/madam./Certainly! /All right. / I see./ Of course.)

3. Explanation (e.g. We were very busy this morning./ There were many orders this morning./ All the rooms are occupied now.);

4. Offering Repair (e.g. We'll inform them to be quiet. / We'll call to check for you. / I'll carry it out.);

5. Promise of Forbearance (e.g. Everything will be ready in five minutes. / Hope that you can go to bed early as planned. / It will be done properly and under my supervision.);

6. Making a Suggestion (e.g. Please relax at the restaurant. / Would you like something to drink while you wait?);

7. Giving the Time Frame for Action (e.g. Just a moment, please. / Please wait a few minutes.);

8. Showing concerns (e.g. Steak is medium? / What's your room number, please?);

9. Gratitude (e.g. Thank you. / Thanks for letting us know of your inconvenience.);

10. Promise of Follow-up Action (e.g. I will investigate how the incident occurred. / Could I call you tomorrow to ask if the problem can be solved?);

11. Empathy (e.g. I understand how you feel about this. I Madam, if I were you, I will be the same as your feeling.);

12) Repetition of Complaints (e.g. The TV cannot be turned on? / You said that your room is disgusting?).

In conclusion, it can be seen that the apology strategies analyzed by many researchers in the previous studies reviewed are similar in use. Therefore, those apology strategies are utilized as the conceptual framework for the present study.

\section{Participants of the Study}

The participants of the study were two different groups of subjects: 32 native English speakers (NE) and 32 Thai EFL learners (TEFL). The former included 19 males and 13 females, with ages ranging from 19 to 52 . All of them came from the U.S.A. The latter group included 12 males and 20 females, ranging in age from 22 to 48 years; they were all M.A. English major students at Buriram Rajabhat University, Thailand.

\section{RESEARCH INSTRUMENT}

The data were collected through a written Discourse Completion Task (DCT). The DCT typically consists of a set of brief situational descriptions designed to elicit a particular speech act [31]. Subjects read the situation and then respond 
in writing to a prompt. The following is an example of a DCT prompt as used in this study:

Situation: You have placed a shopping bag on the luggage rack of a crowded bus. When the bus breaks, your bag falls down and hits a humble woman.

You:

The DCT consisted of 10 different situations, designed to elicit apology strategies. Since the present study has been conducted mainly in a specific situation based on the relative power relationship and the social distance between the interlocutors varied; the interlocutors were set as stranger and intimate. In addition, the power relationship is "high-low", 'low-high' and 'equal' and the social distance is not close.

The DCT was written in English. The following are the 10 provoking-apology situations:

Situation 1: Borrowing the English book from a professor (Low-high)

Situation 2: Asking a new trainee to answer the telephone (High-low)

Situation 3: Forgetting a promise to see movie with close friend (Equal-Equal)

Situation 4: Borrowing a car from your close friend and having an accident (Intimate-Intimate)

Situation 5: A shopping bag falls and hits a humble woman (Stranger-Stranger)

Situation 6: Spilling food on the customer's clothes (Low-high)

Situation 7: Smashing part of the new trainee's laptop (High-low)

Situation 8: Bumping the old woman who carries out some fruits (Stranger-Stranger)

Situation 9: Having lunch with friend and burping uncontrollably (Equal-Equal)

Situation 10: Pushing close friend and falling down on the unclean ground (Intimate- Intimate)

After the design of the situations as well as the content of the DCT was carefully thought out and thoroughly discussed with native speakers of both languages in order to ensure they were sufficiently natural, the instrument was pilot-tested by six respondents: three from each group of the NE and Thai EFL subjects. The main objectives of the pilot test were: 1 ) to carry out a preliminary analysis in order to determine whether the wording, the format and the setting of the situations would present any difficulties; 2) to identify any problematic items in the DCT and remove those elements which did not yield usable data so that the respondents in the second phase would experience no difficulties in answering the DCT; 3 ) to double check that the DCT was clear to all respondents and that there was no confusion as to what they were meant to do; 4) to estimate how long it would take the respondent to answer the apology-provoking situations; and 5) to ensure some sort of validity of the DCT for the data collection and to check its reliability. In other words, to make sure that the DCT is an effective and dependable means of eliciting results which would yield answers to the questions.

\section{DATA COLLECTION PROCEDURES}

The researcher collected the Thai EFL data himself and had the researcher's friend who studied in the U.S.A. collect the NE data. Before completing the DCT, both groups of subjects were given the Informed Consent Form. They completed a demographic questionnaire on their age, gender and years of schooling. Similar to the completion of the Informed Consent Form, both groups of subjects were asked to fill out the DCT. Both groups were told to respond as naturally as possible when completing each of the dialogues. The subjects were also free to ask questions to the administrator regarding the items in the DCT. No time limits were imposed on completing the DCT.

\section{DATA ANALYSIS}

This section explains how the semantic formulas of the DCT data obtained from the subjects were coded. Also, it describes the statistical procedures used to analyze the data.

\section{A. Coding}

The data collected from both groups were analyzed using semantic formulas as "units of analysis". All data from the DCTs were coded according to the apology taxonomy developed by Olshtain and Cohen [10] and Prachanant [13]. For example, in the situation where participants responded to "The borrowing a car from your close friend and having an accident", a response such as "I'm terribly sorry. I had an accident. I will certainly be responsible for the damages and costs", was analyzed as consisting of three units, each falling into corresponding semantic formulas (as shown in the brackets):

(1) I'm terribly sorry.

[apology]

(2) I had an accident

[Explanation]

(3) I will certainly be responsible for the damages and costs.

\section{[Offering repair]}

When a particular response strategy to situation was used more than once in a single response, each use was counted independently.In addition, new types of strategies (semantic formulas) were identified based on this study. To make sure the semantic formulas were correct, three trained teachers of English who were as independent raters, worked independently on recoding, all of the apology strategies in each response according to the initial coding performed by the researcher. Generally, the intercoder reliability value should be more than $80 \%$ [32]. For items on which there was disagreement, all the coders reviewed the coding guidelines, recoded the data together and discussed any discrepancies until they reached a consensus. The intercoder reliability was 94\%. After the coding was completed, the researcher tabulated, quantified, and compared the main discourse components between the two groups. Frequency was chosen as the primary endpoint of this study.

\section{B. Statistical Procedures}

The semantic formulas employed by each group in response to each DCT apology situation were analyzed. The researcher then calculated the total number of frequencies of the apology strategies occurring in each situation from each group by using the percentages. 


\section{FINDINGS}

\section{A. Apology Strategies Used by Native English Speakers and Thai EFL Learners}

This part presents the frequency of apology strategies employed by 64 participants: $32 \mathrm{NE}$ and 32 Thai EFL learners, who were asked to respond to each of 10 apology-provoking situations through the DCT. The overall frequency of semantic formulas of each group is shown in Table I below. Strategies are listed in descending order from reported as those most frequently used to those the least used based on the total frequency counting of both groups.

TABLE I: FREQUENCY OF APOLOGY STRATEGIES USED By NE AND THAI EFL LEARNERS

\begin{tabular}{ccccccc}
\hline \hline \multirow{2}{*}{ Apology Strategies } & \multicolumn{2}{c}{$\mathrm{NE}(\mathrm{n}=32)$} & \multicolumn{2}{c}{$\begin{array}{c}\text { Thai EFL } \\
(\mathrm{n}=32)\end{array}$} & \multicolumn{2}{c}{$\begin{array}{c}\text { All Groups } \\
\text { Combined }\end{array}$} \\
\cline { 2 - 7 } & $\mathrm{f}$ & $\%$ & $\mathrm{f}$ & $\%$ & $\mathrm{f}$ & $\%$ \\
\hline $\begin{array}{c}\text { 1. Expression of } \\
\text { apology }\end{array}$ & 252 & 17.57 & 306 & 21.34 & 558 & 38.91 \\
\hline 2. Offering repair & 167 & 11.65 & 148 & 10.32 & 315 & 21.97 \\
\hline 3. Explanation & 98 & 6.83 & 129 & 9.00 & 227 & 15.83 \\
\hline 4. Showing concerns & 52 & 3.62 & 48 & 3.35 & 100 & 6.97 \\
\hline $\begin{array}{c}\text { 5. Promise of } \\
\text { forbearance }\end{array}$ & 37 & 2.58 & 38 & 2.65 & 75 & 5.23 \\
\hline $\begin{array}{c}\text { 6.Acknowledgement of } \\
\text { responsibility }\end{array}$ & 30 & 2.09 & 36 & 2.51 & 66 & 4.60 \\
\hline 7. Offering help & 29 & 2.02 & 18 & 1.26 & 47 & 3.28 \\
\hline 8. Gratitude & 16 & 1.12 & 7 & 0.48 & 23 & 1.60 \\
\hline 9. Amusement & 14 & 0.98 & 0 & 0.00 & 14 & 0.98 \\
\hline $\begin{array}{c}\text { 10. Exclamation } \\
\text { All Strategies } \\
\text { Combined }\end{array}$ & 4 & 0.28 & 5 & 0.35 & 9 & 0.63 \\
\hline \hline
\end{tabular}

Table I shows the overall frequency of semantic formulas reported of the two different groups: NE and Thai EFL groups through the DCT. The findings reveal that both groups employed 10 different strategies with 1,434 frequencies of semantic formulas. When considering each culture group, it was found that the NE group employed 10 different strategies with 699 frequencies $(48.74 \%$ ) of semantic formulas; whereas, the Thai EFL group employed 9 such strategies with 735 frequencies $(51.26 \%)$ of semantic formulas; "Amusement" was not reported to use. Examination of the overall frequencies of strategy use, however, indicates that the three most frequently used strategies reported were: 1) "Expression of apology" ( $f=558,38.91 \%)$, followed by, "Offering repair" $(\mathrm{f}=315,21.97 \%)$ and "Explanation" $(\mathrm{f}=227,15.83 \%)$, respectively. The least two frequency strategies used, on the other hand, are "Exclamation" ( $\mathrm{f}=9,0.63 \%)$, followed by "Amusement" ( $\mathrm{f}=14,0.98 \%)$ which is found only in NE group.

The followings are the examples of the apology strategies found in this study.

1) Expression of Apology: This strategy represents a strategy used to maintain, or support the apologizer's face.

In addition, it intends to remedy any threat to the apologizee's negative face. The utterances, which serve as an expression of apology, are as follows:

e.g. - I (do) apologize.

- I'm (very/ really/ terribly/ extremely) sorry.

- Excuse me.

- Oops!

2) Offering Repair: This strategy is used to provide the apologizers with help to repair or rectify the unfavorable circumstance.

e.g. - I will have it fixed immediately.

- I will pay for all the damages.

- Please allow me to pay for the repair.

3) Explanation: Explanation or account is a strategy used to give reasons why an unfavorable act has been performed. The following are the utterances from this study.

e.g. - I dropped the laptop accidentally.

- I did some damage to your car while reversing.

- I wasn't looking where I was going.

4) Showing Concerns: This strategy is a strategy used to ask for some facts related to the unfavorable circumstance.

e.g. - Are you alright?

- How did everything go?

- I hope you are not hurt.

5) Promise of Forbearance: This strategy is to inform the apologizers that an immediate repair can be expected/ will be carried out. The apologizees will also undertake to do their best to remedy the unfavorable circumstance.

e.g. - I'm going to return the book tomorrow morning,

I promise.

- I promise to return you today.

- I will bring it to you as soon as possible.

6) Acknowledgement of Responsibility: This strategy is to draw the apologizee's attention to acknowledge and accept the causes of the problems. The utterances used to accept a problem are:

e.g. - It was my fault.

- It's my mistake

- I feel so stupid!

7) Offering Help: This strategy is used when the apologizer would like to offer help the apologizee for the unfavorable circumstance.

e.g. - Can I assist you in any way?

- Please let me help you pick up the fruits.

- May I help you?

8) Gratitude: This strategy is used when the apologizer would like to thank the apologizee for having informed him or her of the helping circumstance. Also, an expression of gratitude is employed when the apologizer wants to end the conversation with his/her interlocutor.

e.g. - Thank you very much.

- Thank you for your help.

- Thank you very much for covering the phone

for me.

9) Amusement: This strategy is used when the apologizer feel embarrassed when he/ she did the unfavorable things.

e.g. - I am such a pig!

- I can't control it (...laugh...)

10) Exclamation: This strategy is used when the apologizer feels surprising or shock with the unfavorable circumstance.

e.g. - Oh, my god!

- Oh, my Gosh!

\section{B. The Patterns of Semantic Formulas Used by the NE and EFL Learners}

This part presents the patterns of apology strategies employed by 64 participants: $32 \mathrm{NE}$ and 32 Thai EFL learners, who were asked to respond to each of 10 apology-provoking situations through the DCT. The ten most patterns of semantic formulas employed in each group are shown in Table II below. 
Patterns are listed in descending order from reported as those most frequently used to those the least used based on the total frequency counting of both groups.

TABLE II: PATTERNS OF SEMANTIC FORMULAS USED By NE AND THAI EFL LEARNERS

\begin{tabular}{|c|c|c|c|c|c|c|}
\hline \multirow[t]{2}{*}{ Apology Strategies } & \multicolumn{2}{|c|}{$\mathrm{NE}(\mathrm{n}=32)$} & \multicolumn{2}{|c|}{$\begin{array}{l}\text { Thai EFL } \\
(n=32)\end{array}$} & \multicolumn{2}{|c|}{$\begin{array}{l}\text { All Groups } \\
\text { Combined }\end{array}$} \\
\hline & $\mathrm{f}$ & $\%$ & $\mathrm{f}$ & $\%$ & $\mathrm{f}$ & $\%$ \\
\hline $\begin{array}{c}\text { 1. Expression of } \\
\text { apology + Offering } \\
\text { repair }\end{array}$ & 82 & 15.10 & 94 & 17.31 & 176 & 32.41 \\
\hline $\begin{array}{c}\text { 2. Expression of } \\
\text { apology + Explanation }\end{array}$ & 68 & 12.53 & 75 & 13.81 & 143 & 26.34 \\
\hline $\begin{array}{l}\text { 3. Expression of } \\
\text { apology + Offering + } \\
\text { Showing concerns }\end{array}$ & 32 & 5.89 & 30 & 5.53 & 62 & 11.42 \\
\hline $\begin{array}{l}\text { 4. Expression of } \\
\text { apology }\end{array}$ & 17 & 3.13 & 30 & 5.53 & 47 & 8.66 \\
\hline 5. Explanation & 24 & 4.42 & 18 & 3.31 & 42 & 7.73 \\
\hline $\begin{array}{c}6 . \text { Expression of } \\
\text { apology + Offering } \\
\text { repair + Explanation }\end{array}$ & 12 & 2.21 & 13 & 2.39 & 25 & 4.60 \\
\hline $\begin{array}{l}\text { 7. Acknowledgement of } \\
\text { responsibility }\end{array}$ & 8 & 1.47 & 8 & 1.47 & 16 & 2.94 \\
\hline $\begin{array}{l}\text { 8. Acknowledgement of } \\
\text { responsibility + Offering } \\
\text { repair }\end{array}$ & 7 & 1.28 & 6 & 1.11 & 13 & 2.39 \\
\hline 9. Offering repair & 4 & 0.74 & 6 & 1.11 & 10 & 1.85 \\
\hline $\begin{array}{c}\text { 10. Expression of } \\
\text { apology }+ \text { Offering help }\end{array}$ & 4 & 0.74 & 5 & 0.92 & 9 & 1.66 \\
\hline $\begin{array}{c}\text { All Strategies } \\
\text { Combined }\end{array}$ & 258 & 47.51 & 285 & 52.49 & 543 & 100.00 \\
\hline
\end{tabular}

As shown in Table II, it was found that both groups of participants employed the patterns of semantic formulas in responding to the provoking-apology situations in the similar way. The three most frequently use of the patterns of semantic formulas employed by both groups were "Expression of apology + Offering repair" with the frequencies of 176 (32.41\%): NE $=82$ (15.10\%), Thai EFL=94 (17.31\%), followed by "Expression of apology + Explanation" with the frequencies of 143 (26.34\%): $\mathrm{NE}=68$ (12.53\%), Thai $\mathrm{EFL}=75(13.81 \%)$, and "Expression of apology + Offering repair + Showing concerns" with the frequencies of 62 (11.42\%): $\mathrm{NE}=32$ (5.89\%), Thai $\mathrm{EFL}=30 \quad(5.53 \%)$, respectively.

The followings are the examples of each pattern of semantic formulas:

1) Expression of apology + Offering repair- "I'm extremely sorry. I will pay for all the damages."

2) Expression of apology + Explanation- "I'm sorry. I did some damage to your car while reversing."

3) Expression of apology + Offering repair + Showing concerns- "I apologize for that. I will buy some new fruits for you. Are you okay?"

4) Expression of apology- "I'm terribly sorry."

5) Explanation- "I wasn't looking where I was going. "

6) Expression of apology + Offering repair + Explanation -

"So sorry, I will buy a new one for you. I dropped the laptop accidentally."

7) Acknowledgement of responsibility- "It is my mistake, madam."

8) Acknowledgement of responsibility + Offering repair- "Oh, how clumsy I am! I will buy a new one for you."

9) Offering repair- "I will take care of all damages."

10) Expression of apology + Offering help- "Please accept my apology. What can I help you?"

\section{DISCUSSION}

\section{A. Apology Strategies Used by the NE and Thai EFL Learners}

Examining the data presented in Table I, 10 apology strategies were used by the NE and Thai EFL learners. The three most strategies used were "Expression of apology", "Offering repair" and "Explanation". These findings are consistent with the claims made by all linguists who conducted the studies on apology [4], [8], [10], [11], [13]-[16], [21], [22], [24], [26], [33]-[35] that with respect to the languages studies in their research, the three major semantic formulas mentioned were 'universal'. Having said that all these strategies were normally used by both the native and non-native speakers of all varieties of English. This could be said that the situations employed in the present study are as in the daily life so that the findings of those studies were similar in employing the strategies. This is similar to the conclusion of Olshtain [16] that 'it seems to be possible to identify universal manifestations of strategy selection'. In addition, this strategy was claimed by Suszcynska [21] that it was commonly called for in most situation investigated. Also, the most explicit realization of apology strategy is "Expression of apology" which is called for in each situation by both two groups. This could be explained that both groups have the perception that using "Expression of apology" is compulsory in each apology; "I'm (intensifiers) sorry is the most common used. This is consistent with the claims made by Owen [17] that "Expression of apology" is the most conventionalized and routinised, being as it was in the center of the speech act of apologizing in the study and representing verbal routine or syntactic - semantic formula which are regularly used to fulfill a specific communicative function.

\section{B. The Patterns of Semantic Formulas Used by the NE and Thai EFL Learners}

The finding revealed that the two most popular patterns used of semantic formulas are "Expression of apology + Offering repair" and "Expression of apology + Explanation". This could be explained by the fact that both groups of the participants have the perception that using "Expression of apology" is compulsory in each provoking-apology situation, and "Offering repair" or "Explanation" should be called for in order to decrease the offend of the apologizee. As Owen [17] stated that "Expression of apology" is the most conventionalized and routinised, being as it was in the center of the speech act of apologizing in the study and representing verbal routine or syntactic - semantic formula which are regularly used to fulfill a specific communicative function. This finding is similar to the studies of Tuncel [33], Istifci [34] and Alfattah [35] who concluded that the three most patterns used in apology situations are "IFID (Apology) + Explanation" and "IFID (Apology) + Promise and forbearance" and "IFID (Apology) + Offering repair", respectively.

\section{CONCLUSION}

The results of this study suggested that in some situations Thai EFL learners approached native speaker norms in the use 
of apology strategies. However, in some situations there were different in the use of apologies. This may be assumed that L1 (Thai) have an influence on the use of apologies in Thai EFL group. As mentioned in scope and limitation of the study, it is difficult to generalize the findings because the data were collected from $32 \mathrm{NE}$ and 32 Thai EFL learners. However, the findings from this study suggest opportunities for building cross-cultural communications across continents. The results have implications for teaching and learning of English as an L2 in the cross-cultural contexts. That is, to raise pragmatic awareness in the English classroom, language teachers should introduce learners the clips of feature films or videotaped television programs such as news shows and business talk shows which illustrate various responses to apology interaction or any other speech act behaviors between native speakers of English [36], [37]. Using audiovisual media is especially useful in an EFL environment like Thailand where the authentic target language is not input from native speakers of target language is not easily available. The teachers could encourage the pragmatic awareness of learners by discussing status relationships between the interlocutors, and by comparing the differences, as well as the similarities between the ways English speakers in the clips performed any given speech act and the way learners would do so in Thai. This kind of activity will help learners realize that speakers from different cultures may not always share the same sociolinguistic rules of performing speech acts as their own.

\section{REFERENCES}

[1] D. Hymes, "Models of the interaction of language and social life," in Directions in Sociolinguistics: The Ethnography of Communication, J. J. Gumperz et al., Eds. NY: Newbury House, 1972, pp. 35-71.

[2] G. Kasper, "Pragmatics transfer," Second Language Research, vol. 8, no. 3, pp. 203-231, 1992.

[3] E. Olshtain and A. Cohen, "Teaching speech act behavior to nonnative speakers," in Teaching English as a Second or Foreign Language, M. Colce-Murcia, Ed. NY: Newbury House, 1988, pp. 154-165.

[4] M. Tamanaha. Interlanguage Speech Act Realization of Apologies and Complaints: The Performances of Japanese L2 Speakers in Comparison with Japanese L1 and English L1 Speakers, Doctoral dissertation, University of California, Los Angeles, USA, 2003.

[5] G. Kasper and S. Blum-Kulka, "Interlanguage pragmatics: An introduction," in Interlanguage Pragmatics, G. Kasper and S. Blum-Kulka, Eds. pp. 139-154, NY: Oxford University Press., 1993.

[6] J. R. Searle, Speech Acts, Cambridge University Press, 1969.

[7] J. Kwon, Pragmatic Transfer and Proficiency in Refusals of Korean EFL Learners, Doctoral dissertation, Boston University, 2003.

[8] A. D. Cohen and E. Olshtain, "Developing a measure of sociocultural competence: The case of apology," Language Learning, vol. 31, no. 1, pp. 113-134, 1981.

[9] M. Mir, "Do we all apologize the same?-An empirical study on the act of apologizing by Spanish speakers learning English," in Pragmatics and Language Learning, L. Bouton and Y. Kachru, Eds. vol. 3, pp. 18-36, Urbana-Champaign: University of Illiniois, 1992.

[10] E. Olshtain and A. Cohen, "Apology: A speech act set," in Sociolinguistics and Language Acquisition, N. Wolfson and E. Judd, Eds. pp. 18-35, New York: Newbury House, 1983.

[11] R. M. Reiter, Linguistic Politeness in Britain and Uruguay: A Contrastive Study of Requests and Apologies, Philadelphia: John Benjamins North America, 2000.

[12] T. Takahashi and L. Beebe, "Cross-linguistic influence in the speech act of correction," in Interlanguage Pragmatics, G. Kasper and S. Blum-Kulka, Eds. pp. 138-157, Oxford University Press, 1993.

[13] N. Prachanant, Pragmatic Transfer in Responses to Complaints by Thai EFL Learners in the Hotel Business, Unpublished $\mathrm{PhD}$ Dissertation. Suranaree University of Technology, 2006.

[14] A. Trosborg, "Apology strategies in native-nonnative speakers of English,” Journal of Pragmatics, vol. 11, no. 1, pp. 147-167, 1987.
[15] Trosborg, Interlanguage Pragmatics: Requests, Complaints and Apologies, Berlin: Mouton, 1995.

[16] E. Olshtain, "Sociocultural competence and language transfer: The case of apology," in Language Transfer in Language Learning, S. Gass and L. Selinker, Eds. pp. 232-249, Newbury House, 1983.

[17] M. Owen, Apologies and Remedial Interchanges: A Study of Language Use in Social Interaction, Mouton Publishers, 1983.

[18] S. Blum-Kulka, "Learning how to say what you mean in a second language: A study of the speech act performance of learners of Hebrew as a second language," Applied Linguistics, vol. 3, pp. 29-59, 1982.

[19] A. D. Cohen, E. Olshtain, and D. S. Rosenstein, "Advanced EFL apologies: What remains to be learned?" International Journal of the Society of Language, vol. 12, no. 6, pp. 51-74, 1986.

[20] N. Maeshiba, N. Yoshinaga, G. Kasper, and S. Rose. "Transfer and proficiency in interlanguage apology," in Speech Act across Cultures: Challenges to Communication in a Second Language, S. Gass and J. Neu, Eds. pp. 155-187, Berlin: Mouton, 1996.

[21] M. Suszczynska, "Apologizing in English, Polish and Hungarian: Different languages, different strategies," Journal of Pragmatics, vol. 31, no. 8, pp. 1053-1065, 1999.

[22] S. Intachakra, "Contrastive pragmatics and language teaching: Apologies and thanks in English and Thai," RELC Journal, vol. 35, no. 1, pp. 37-62, 2004.

[23] S. Blum-Kulka, J. House, and G. Kasper, "Investigating cross-cultural pragmatics: An introductory overview," in Cross-cultural Pragmatics: Requests and Apologies, S. Blum-Kulka, J. House and G. Kasper, Eds. pp. 1-37, 1989.

[24] J. Holmes. "Apologies in New Zealand English," Language in Society, vol. 19, no. 2, pp. 155-199, 1990.

[25] E. Rintell and C. Mitchell, "Studies of requests and apologies: An inquiry into method," in Cross-Cultural Pragmatics: Requests and Apologies, S. Blum-Kulka et al., Eds. pp. 248-272, 1989.

[26] H. J. Vollmer and E. Olshtain, "The language of apologies in German," in Cross-Cultural Pragmatics: Requests and Apologies, S. Blum-Kulka, J. House and G. Kasper, Eds. pp. 197-218, Norwood, NJ: Ablex, 1989.

[27] M. L. Bergman and G. Kasper, "Perception and performance in native and nonnative apology," in Interlanguage Pragmatics, G. Kasper et al., Eds. pp. 82-107, Oxford University Press, 1993.

[28] J. R. Searle, "The classification of illocutionary acts," Language in Society, vol. 5, pp. 1-24, 1976.

[29] E. Goffman, Relations in Public, New York: Harper \& Row, 1971.

[30] Fraser, "On apology," in Conversationalroutine, F. Coulmas, Ed. pp. 259-271, The Hague: Mouton, 1981.

[31] G. Kasper and K. R. Rose, "Pragmatics in language teaching," in Pragmatics in Language Teahing, K. R. Rose and G. Kasper, Eds. pp. 2-9, Cambridge: Cambridge University Press, 2001.

[32] Wannaruk, Back-Channel Behavior in Thai and American Casual Telephone Conversations, Doctoral Dissertation, University of Illinois at Urbana-Champaign, USA, 1997.

[33] R. Tunel, Speech Act Realizations of Turkish EFL Learners: A Study on Apologizing and Thanking, Unpublished PhD Dissertation. Anadolu Universitesi, SBE, 1999.

[34] Istifci, "The use of apologies by EFL learners," English Language Teaching, vol. 2, no. 3, pp. 15-25, 2009.

[35] M. H. A. Alfattah, "Apology strategies of Yemeni EFL university students," MJAL, vol. 2, no. 3, pp. 223-249, 2010.

[36] K. R. Rose, Pragmatics in Teacher Education for Nonnative-Speaking Teachers: A Consciousness-Raising Approach, Language, Culture and Curriculum, vol. 10, pp. 125-137, 1997.

[37] K. Tanaka, "Developing pragmatic competence: A learners-as-researchers approach," TESOL Journal, vol. 6, pp. 14-18, 1997.

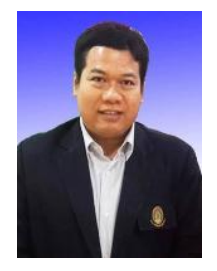

Nawamin Prachanant is an Assistant Professor at Buriram Rajabhat University, Thailand. He received a B.Ed. with the $1^{\text {st }}$ class honour from Srinakarinwirot University Mahasarakham, an M.Ed. in English from Mahasarakham University, and a Ph.D. in English language studies from Suranaree University of Technology, Thailand. Currently, he is the Chair of the M.A. Programme in English at Buriram Rajabhat University. His academic interests include discourse analysis, sociolinguistics, speech acts, pragmatics, English for specific purposes and course development. 